\title{
Filigrane
}

Écoutes psychothérapiques

\section{Le corps. Sur le divan, dans le fauteuil. Argumentaire pour les dossiers 2009 de Filigrane}

\section{Comité de rédaction}

Volume 16, numéro 2, automne 2007

Les hauts lieux et non-lieux du rêve II

URI : https://id.erudit.org/iderudit/016927ar

DOI : https://doi.org/10.7202/016927ar

Aller au sommaire du numéro

Éditeur(s)

Revue Santé mentale au Québec

ISSN

1192-1412 (imprimé)

1911-4656 (numérique)

Découvrir la revue

Citer ce document

Comité de rédaction (2007). Le corps. Sur le divan, dans le fauteuil.

Argumentaire pour les dossiers 2009 de Filigrane. Filigrane, 16(2), 112-113.

https://doi.org/10.7202/016927ar 


\section{Le corps. Sur le divan, dans le fauteuil. Argumentaire pour les dossiers 2009 de Filigrane}

\section{comité de rédaction}

$\mathrm{P}$

our sa dix-huitième année de parution, Filigrane se propose d'étudier le corps dans le contexte de l'espace transféro-contretransférentiel. Non le corps de la médecine ou de la psychosomatique, mais celui porteur de messages, lieu d'inscriptions, de subjectivation et d'enchâssement d'une parole. La psychanalyse parle peu de la réalité du corps dans le contexte du travail clinique. Aux étudiants de la «talking cure», on recommande, par exemple, de n'interpréter que ce qui s'y dit verbalement. Le clinicien et son patient: de purs esprits? Dans l'intimité de la rencontre clinique, les corps des deux protagonistes témoignent pourtant de leur réalité charnelle par un langage fait, entre autres, d'odeurs, de borborygmes, de sueur, de tensions musculaires. Ce langage peut-il constituer un message à l'autre ? Habituellement, le clinicien considère inopinées les manifestations perceptibles de son corps, les jugeant comme une transgression de son idéal de neutralité bienveillante. Pourtant, y a-t-il moins neutre que le corps bien soigné ou non, parfumé à la nicotine, à l'eau de toilette ou non, hâlé ou blême, d'un clinicien/d'une clinicienne, portant des vêtements seyants ou fripés, une nouvelle coiffure, une tête grise, des cheveux teints ? De quel corps s'occupe donc la psychanalyse ? Que cache et dévoile, à notre «corps défendant», cet étrange corps à corps de deux adultes sexués?

Filigrane demande à ses auteurs de s'intéresser aux enjeux de cette rencontre dans l'espace transféro-contretransférentiel et d'élaborer une réflexion sur ce thème à partir de leur expérience clinique.

Filigrane se demande, par exemple, si les postures, les maniérismes, les tics, les manières de vêtir, orner, nourrir, traiter son corps peuvent être lus comme les vestiges d'une histoire passée, des hiéroglyphes à décrypter par le clinicien. Peuton considérer certaines manifestations corporelles comme un protolangage? Les odeurs envahissantes : parfois barrières repoussantes, parfois parfums séduisants ; la tessiture de la voix : un contenant contredisant parfois le contenu; le tonus musculaire d'une posture: parfois annulation d'une parole verbale. Un corps silencieux peut être tellement présent!

S'il est vrai que nous portons notre race et notre culture inscrites sur notre corps et ses oripeaux, quel statut donner à ses manifestations viscérales, hormonales, cutanées? Quel âge a le corps dont le patient hypochondriaque décrit les dangers 
appréhendés? Quel message envoient les corps androgynes de certains patients, devant lesquels se brouillent les repères identificatoires du clinicien? À quelle sorte de rencontre invitent les corps sculptés par le culturisme ou la chirurgie et qui donnent tant à voir? Un corps peut en cacher un autre... Il y a parfois trop de corps ou alors une illusion d'incorporalité, telle celle de Narcisse qui ne sut prendre son propre corps que comme celui d'un autre.

Comment aborder l'occupation de l'espace physique par les deux protagonistes, le frôlement des corps dans le corridor ou la salle d'attente, celui des mains dans l'échange d'argent? Comment traiter ce qui a pour le patient un statut d'idiosyncrasie et permettre l'émergence d'une possibilité de sens? Regards ou paroles devant un corps dont la retenue évoque la possible éclosion de l'acte?

Côté fauteuil, quelle dynamique initient les cliniciens en invitant leurs patients à étaler leur corps sur un divan trop (?) horizontal, alors que d'autres divans permettent de dérober au regard de l'analyste tant le visage que les aspects les plus sexuées du corps? Faut-il le rappeler, le corps de l'analyste, lui, est presque totalement hors de vue. Et les jeux autour de la couverture posée sur le pied du divan? Et le ventre fécond de la femme analyste qui s'arrondit silencieusement sous le regard de son patient? Quel statut réserver aux endormissements indus, aux picotements, engourdissements, céphalées, émois qui surgissent de façon imprévue?

Bref, nombreuses sont les anecdotes qu'échangent les cliniciens au sujet des corps de leurs patients et de leur propre corps dans l'espace clinique: les dysharmonies perçues, les malaises ressentis ne sont pas rares. Mais comment donner un autre statut théorique à ces anecdotes ? Comment pratiquer la talking cure pour que le perçu et le ressenti deviennent une des langues vives utilisées entre le clinicien et son patient?

Filigrane invite ses auteurs à lui faire parvenir pour le $1^{\text {er }}$ septembre 2008 un texte d'environ quinze feuillets rédigé selon les normes de rédaction de la revue à l'adresse courrielle suivante : richard.helene@uqam.ca. 